\title{
The Efficacy of Behavioral and Rational Emotive Behavior Therapies on Conduct Disorder Among Juvenile Delinquents in Selected Rehabilitation Schools in Kenya
}

\author{
Naomi James ${ }^{1,}$, , Maxwell Philip Omondi \\ ${ }^{1}$ Department of Psychology and Counseling, School of Human and Social Sciences, Daystar University, Nairobi, Kenya \\ ${ }^{2}$ Department of Biostatistics and Epidemiology, School of Health Sciences, Mount Kenya University, Thika, Kenya \\ Email address: \\ naomijimmy@gmail.com (N. James),maxwellomondi@gmail.com (M. P. Omondi) \\ ${ }^{*}$ Corresponding author
}

To cite this article:

Naomi James, Maxwell Philip Omondi. The Efficacy of Behavioral and Rational Emotive Behavior Therapies on Conduct Disorder among Juvenile Delinquents in Selected Rehabilitation Schools in Kenya. American Journal of Applied Psychology.

Vol. 10, No. 1, 2021, pp. 1-9. doi: 10.11648/j.ajap.20211001.11

Received: November 11, 2020; Accepted: November 27, 2020; Published: January 12, 2021

\begin{abstract}
The purpose of this study was to determine the effectiveness of behavioral and rational emotive behavior therapies (REBT) on conduct disorder among juvenile delinquents. This was a quasi-experimental study design with Kabete Rehabilitation School representing the experimental group and Wamumu Rehabilitation School representing the control group. A total of 94 respondents aged between 13 and 17 years from Kabete and Wamumu rehabilitation schools in Kenya participated in the study (47 for each study arm). A socio-demographic questionnaire was administered, in addition to a selfadministered Child Behavior Checklist (CBCL-YSR) Youth Self Report for ages 11-18 (2001) completed at baseline, midline ( 3 months post-intervention) and endline (6 months post intervention). CBCL is a standardized tool with a proven validity and reliability of 0.82 . The two groups were comparable statistically with respect to key socio-demographic characteristics namely type of facility, age, employment status with the exception of class. Data was analyzed using Statistical Package for the Social Sciences version 20.0 (20). Presentations were done using profile plots and tables. The experimental group showed a steady decline in the mean CD scores over the study period from 19.96 (SD: 5.069) at baseline to mean of 8.26 (SD: 2.625) at endline $(\mathrm{p}<0.0001)$. The control group had a rather staggered decline from mean of 14.94 (SD: 3.953) at baseline to 11.81 (SD: $4.332)$ at end-line $(\mathrm{P}>0.05)$. Difference-in-differences $(\mathrm{DiD})$ model was used to determine the efficacy of the intervention at post-treatment one and post-treatment two. The DiD estimators at midline was $-1.393(\mathrm{p}<0.0001)$ and at end-line was -1.204 $(p<0.0001)$ after controlling for class. The study established a statistically significant reduction of conduct disorder symptoms from a mean of 19.96 at baseline to 8.26 at post-treatment two and this was significant at $p<0.001$, indicating the effectiveness of behavioral and REBT therapies in treating conduct disorder. Based on the study findings, it is recommended that behavioral and REBT therapies be integrated in the juveniles' rehabilitation program.
\end{abstract}

Keywords: Conduct Disorder, Juvenile Delinquents, Rehabilitation, Adolescents

\section{Introduction and Background}

Conduct disorder is a behavior that violates the rights of other people, with mild symptoms manifested in childhood and advancing to other severe problem behaviors at adolescence and adulthood. A person with conduct disorder presents with antisocial behaviors of offending others through aggressive conduct and other unacceptable acts in the society [1].
Conduct disorder is one of the commonest disorders that affect children from early childhood and manifests mostly during school-going age and adolescence [2]. It sometimes presents with other disorders like attention deficit hyperactive, opposition defiant, substance abuse and depression [3-5]. Children who have portrayed conduct behavioral problems, committed crimes and have been convicted are placed in rehabilitation centers for the purpose of correcting their behaviors. 
Children with conduct disorder have difficulties with interpersonal relationships, emotional regulation and cognitive skills [6]. Other difficulties such children portray include deficits in perceptions, interpretation of cues and processing of information [7, 8]. Additionally, children with conduct disorder often perceive their environment as hostile and hence respond with aggression to the people around them $[9,10]$.

Studies have shown that conduct disorder is increasing and the prevalence rate in terms of gender is higher with boys compared to girls $[10,11]$. According to a report compiled for the British Columbia's Ministry of Children and Family Development, a large-scale community-based epidemiological survey indicated the prevalence of conduct disorder in the United States, Canada and British Columbia at $4.2 \%$ [12]. In the United States, the prevalence of conduct disorder was estimated between 9 and 9.5\% [13, 14]. Among juvenile delinquents in the USA, studies have indicated prevalence rates ranging between $40 \%$ and $52.8 \%$ [15-17]. In India, conduct disorder among 10-15 year old boys and girls was found at $4.58 \%$ [18] whereas in Nigeria, the prevalence in a particular mixed school, average age 13 years, was $15.82 \%$ [19]. In Kenya, psychological disorders assessed among juveniles in the Nairobi juvenile court and two rehabilitations center established the prevalence of conduct disorder at $45 \%$ and $30.4 \%$ respectively $[20,21]$.

Conduct disorder is caused by multiple interacting factors including biological, social and psychological [9]. Some of these factors expose children to very distressful situations which affect them in their social, emotional and physical wellbeing, academic development and generally in their daily functioning [22]. One of the key contributing factors to conduct disorder is parenting [5]. Parents who have poor relationships and little interaction with their children expose them into the risks of developing conduct disorder $[2,12,13$, 23]. An uninvolved parent is neither emotionally available nor attuned to the needs of a child [24, 25], a factor associated with increased chances of developing callousunemotional traits [26], severe reactive aggression, lack of empathy and guilt.

A hostile home environment is also a contributing factor to the development of conduct disorder, especially in situations where children are exposed to violence, instability and parents stress and aggressive behavior [2, 13, 27-30]. Studies show higher prevalence of conduct disorder among children from single-parent families, large, low economic status, dysfunctional families and the mental health of parents [9, 20, 29, 31-34]. Additionally, punitive measures of correcting wrong behavior applied by parents on children is mostly interpreted as rejection which is a risk factor to the development of conduct disorder [25].

Children who are exposed to child abuse have a higher risk of developing conduct disorder [28, 35]. Experiences such as being denied basic needs, negligence, and maltreatment are some of the abuses children face which threaten their normal life functioning [9, 10, 36, 37]. Sexual abuse and assault are attributed to externalizing problem behaviors such as conduct disorder [10, 36]. Moreover, social learning and modeling has an effect on children who learn unacceptable behaviors from others through keeping company and peer pressure [2, 38]. Some children report having been introduced by their friends or forced into delinquent behaviors [29, 39].

The effects of conduct disorder are not only experienced by children alone, but also the family and the entire society $[4,33]$. Children with conduct disorder experience rejection from peers and families, difficulties with academics, antisocial personality as they transition to adulthood, poor interpersonal relationships, criminal activities and difficulties with employment $[6,13,26,28,40]$. Behaviors such as destruction of property, causing harm, breakings and illegal use of weapons greatly affect the society and the cost of rehabilitation programs is also high due to the training, personnel and boarding facilities required $[13,40]$.

Considering all the effects of conduct disorder on the individual, family and society, it is important to emphasize the need to provide treatment especially among juvenile delinquents. Treatments that have been effective integrate aspects of correcting cognitions with behavioral change, emotional regulation and problem-solving skills training. [7] shows that contingency management programs and cognitive behavioral skills trainings are interventions that produce positive results in treating conduct disorder This study used behavioral and rational emotive behavior therapy (REBT) which are effective in character disorders, self-management and social skills [41].

One of the assumptions of behavioral therapy is that behavior is learnt [42, 43] and the main focus of this approach is behavior change which addresses both covert (internalizing) and overt (externalizing) problems [9, 42]. The use of behavioral therapy demands that clients be actively involved in the process and be willing to monitor their behavior in and outside therapy. This is done through contingency management plan where a specific behavior is targeted, goals are set, reinforcement and mild punishment are used [8]. This study used behavioral therapy specifically utilizing operant conditioning techniques which aims at achieving change in behavior through learning and unlearning, reinforcement, punishment, modeling and observation. Operant conditioning techniques increase the desired behavior, terminate the undesirable behavior, and can effectively equip individuals with socially-acceptable behavior [3, 42, 44]. Behavioral therapy has become one of the most effective therapies of treating conduct disorder. In a review of studies done between 1962 and 2002, 71\% of the 236 studies used behavioral therapy to treat conduct-related problems [45]. A study involving boys with disruptive behavior indicated an effect size of.55 in the experimental group compared to the control group [46], while other studies have registered significant changes in boys with behavior problems [47-49].

In this study, REBT which is one of the cognitive behavior theories was used, and specifically incorporated problemsolving skills training which addresses new ways of cognitive processing, behavior change, identification of irrational 
beliefs and change of maladaptive emotional responses such as anger and guilt $[9,50,51-53]$. This study used techniques such as role playing, disputing irrational beliefs, emotional regulation, psycho-education, and problem solving. REBT has been used successfully in training anger management, problem solving and changing irrational thinking [54, 55]. Additionally, incorporating REBT with problem-solving skills training has produced tremendous positive change in behavioral problems [41].

\section{Procedure and Method}

This was a quasi - experimental study design with an experimental (Kabete Rehabilitation School) and control group (Wamumu Rehabilitation School) conducted in Nairobi and Kirinyaga counties in Kenya. The respondents were purposively sampled. The experimental group was treated with behavioral and REBT interventions while the control group did not receive any treatment.

\subsection{Participants}

A total of 94 children from Kabete and Wamumu rehabilitation schools in Kenya participated in the study. From a universe of 167 children, 94 respondents met the eligibility criteria -47 representing each study arm - total 94 respondents. Eligibility criteria included school going children between ages of 13 - 17 years who presented with conduct disorder. The children had been placed for rehabilitation due to criminal offences like assault, harming people, truancy, stealing, associating with criminal gangs, possession of drugs and breaking into premises. Participation was voluntary and all the children agreed to be enrolled in the study.

\subsection{Procedure}

Participants completed a social demographic questionnaire and the child behavior checklist youth self report for ages 1118 (2001). This tool is designed to measure scales such as rule-breaking and aggressive behavior [56]. 94 participants met the criteria for conduct disorder. Permission to conduct the study was sought from all relevant authorities. All the children were given information about the purpose, nature and duration of the study in addition to their role and rights. Since the children were incarcerated, consent to participate was signed by the school managers on behalf of the parents and the children assented. In the experimental group, participants were placed in groups of 8 to 10 based on developmental levels of moral reasoning [57] for a period of sixteen weeks. During this period, treatment was offered using behavioral and REBT therapies. At post-treatment one which was after three months, participants completed the child behavior checklist youth self report (11-18) to assess changes in delinquent behavior, attitude and thought patterns. The final assessment which was post-treatment two (endline) was conducted after three months using the child behavior checklist youth self report (11-18).

\subsection{Data Collection Instruments}

In this study, the researcher formulated a self-administered questionnaire to collect socio demographic data like age, class, offence, parents' marital status and employment. The Child Behavior Checklist Youth-Self-Report (CBCL-YSR) for Ages 11-18 (2001) was also used. This tool was developed by Achenbach in 2001 and it is one of Achenbach System of Empirically Based Assessments [56]. The questionnaire has 112 questions rated at a likert scale from 0 2 and measures conduct disorder and other behavioral presentations [58].

\section{Results}

This study sought to determine the efficacy of behavior and REBT therapies on conduct disorder among juvenile delinquents. Pearson's chi-square test for independence was used to test significant difference between the control and experimental group by key socio-economic-demographic characteristics namely religion, class and employment status of parent/caregiver (self/formal) among juvenile delinquents in Kabete and Wamumu rehabilitation schools (Table 1).

Table 1. Differences between Control and Experimental Groups.

\begin{tabular}{|c|c|c|c|c|}
\hline Characteristics & $\begin{array}{l}\text { Experimental (Kabete Rehabilitation } \\
\text { School) }\end{array}$ & $\begin{array}{l}\text { Control (Wamumu Rehabilitation } \\
\text { School) }\end{array}$ & $\chi^{2}$ statistics & p-value* \\
\hline Number of respondents & 47 & 47 & - & - \\
\hline Type of facility & Government Rehabilitation Schools & Government Rehabilitation Schools & - & - \\
\hline \multicolumn{5}{|c|}{ 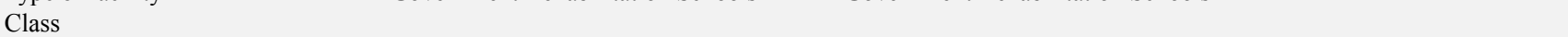 } \\
\hline 4 & $0.0 \%(0 / 10)$ & $100.0 \%(10 / 10)$ & \multirow{5}{*}{16.262} & \multirow{5}{*}{0.003} \\
\hline 5 & $28.6 \%(4 / 14)$ & $71.4 \%(10 / 14)$ & & \\
\hline 6 & $62.5 \%(15 / 24)$ & $37.5 \%(9 / 24)$ & & \\
\hline 7 & $60.0 \%(15 / 25)$ & $40.0 \%(10 / 25)$ & & \\
\hline 8 & $61.9 \%(13 / 21)$ & $38.1 \%(8 / 21)$ & & \\
\hline \multicolumn{5}{|c|}{ Employment status (self/formal) } \\
\hline No & $44.4 \%(16 / 36)$ & $55.6 \%(20 / 36)$ & \multirow{3}{*}{0.720} & \multirow{3}{*}{0.396} \\
\hline Yes & $53.4 \%(31 / 58)$ & $46.6 \%(27 / 58)$ & & \\
\hline \multicolumn{3}{|l|}{ Religion } & & \\
\hline Christian & $51.2 \%(43 / 84)$ & $48.8 \%(41 / 84)$ & \multirow{2}{*}{0.448} & \multirow{2}{*}{0.503} \\
\hline Muslim & $40.0 \%(4 / 10)$ & $60.0 \%(6 / 10)$ & & \\
\hline
\end{tabular}

*p-values generated using Pearson's $\chi^{2}$ tests for independence 
According to Table 1, there was a significant difference in the number of respondents per class between control and experimental groups $(\mathrm{p}=0.003)$. The experimental group had more respondents in the upper classes (6-8) compared to the control group. Considering the employment status of juveniles' parents/caregivers, there was no significant difference between the control and the experimental groups. The two groups were recruited from government boarding rehabilitation schools and the number of respondents was equal in both schools. The two groups were almost similar and therefore comparable.

Table 2 presents the mean conduct disorder scores at baseline, post-treatment one and post-treatment two. The experimental group (KRS) received Rational Emotive Behaviour Therapies (REBT) and behavior therapies while the control group (WRS) did not receive any treatment.

Table 2. Descriptive Analysis of CD Scores at Baseline and Post-Treatment.

\begin{tabular}{llll}
\hline & Experimental & Control & Total* \\
\hline Baseline scores & $19.96(5.069)$ & $14.94(3.953)$ & $17.44(95 \%$ CI: $16.510-18.383)$ \\
Post-treatment one scores & $10.81(2.983)$ & $14.57(4.292)$ & $12.691(95 \%$ CI: $11.933-13.450)$ \\
Post-treatment two scores & $8.26(2.625)$ & $11.81(4.332)$ & $10.032(95 \%$ CI: $9.299-10.765)$ \\
\hline
\end{tabular}

*Wilk’s Lambda for Time*Arm interaction is significant at $\mathrm{p}<0.0001$

As shown in Table 2, the experimental group indicated a steady decline in the mean conduct disorder scores over the study period from the mean at baseline of 19.96 (SD: 5.069) to mean of $8.26(\mathrm{SD}: 2.625)$ at post-treatment two. The control group had a rather staggered decline from mean of 14.94 (SD: 3.953 ) at baseline to 11.81 (SD: 4.332) at posttreatment two. This implied that both groups recorded a reduction of conduct disorder symptoms although the experimental group had greater reduction compared to the control group.

Figure 1 shows the trend in measurements between the control and experimental group at baseline, post-treatment one and two.

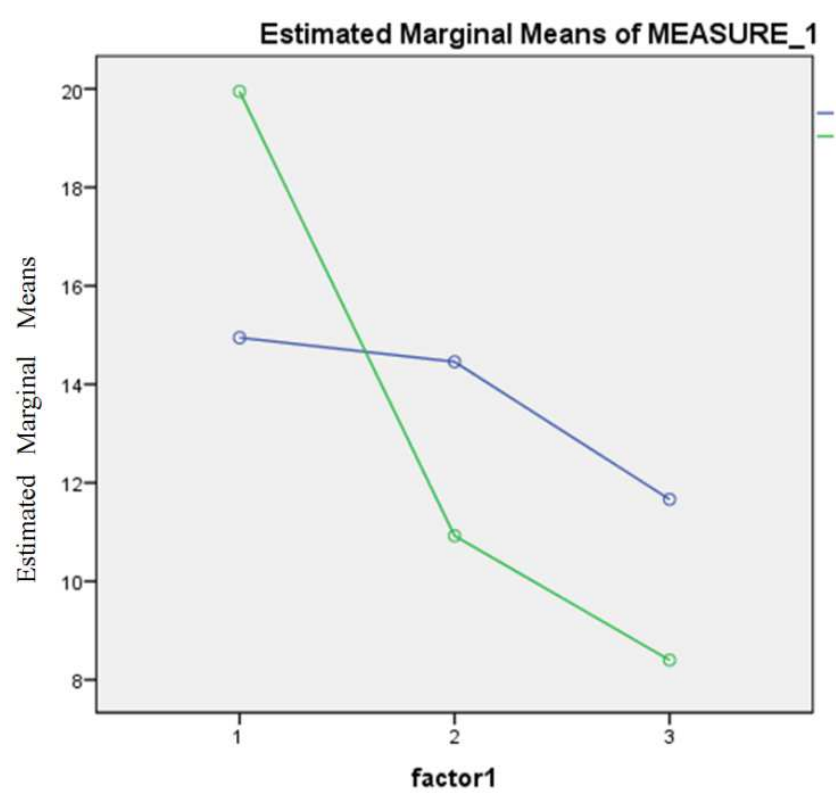

Figure 1. Profile Plot Showing the Trend in Measurements.

In figure 1 , the profile plot demonstrated the impact of the intervention on the mean conduct disorder scores over the two post-treatment periods across the control and experimental groups. The line graphs showed a much stepper decline in the conduct disorder scores in the experimental group as opposed to the control group after controlling for class. The difference at post-treatment two between control and experimental group was wider as compared to baseline and post-treatment one. This depicted the behavior and REBT therapies having an impact at post-treatment one and post-treatment two among juvenile delinquents in Kabete Rehabilitation School.

Table 3 presents the marginal difference between baseline measurements in conduct disorder scores and post-treatment one and two in both control and experimental groups.

Table 3. Marginal Difference between Baseline and Post-Treatment Scores.

\begin{tabular}{lllll}
\hline \multirow{2}{*}{ Time (a) } & Time (b) & $\begin{array}{l}\text { Mean Difference } \\
\text { (a-b) }\end{array}$ & $\begin{array}{l}\text { Std. } \\
\text { Error }\end{array}$ & p-value \\
\hline Baseline & Post-treatment One & 4.755 & 0.342 & $<0.0001$ \\
& Post-treatment Two & 7.415 & 0.428 & $<0.0001$ \\
\hline
\end{tabular}

Based on estimated marginal means, there was a statistically significant difference between baseline and posttreatment one $(p<0.0001)$, and between baseline and posttreatment two $(\mathrm{p}<0.0001)$ after controlling for the respondents' class. This demonstrated that there was a statistically significant difference between baseline and posttreatment one and baseline and post-treatment two as a result of the behavior and REBT therapies.

Table 4 shows estimate treatment effects by comparing the baseline and post-treatment differences using Difference-inDifference. These were determined using ordinary least squares after controlling for class as a possible confounder.

Table 4. Difference-in-Differences Estimates of Behavior and REBT Therapies.

\begin{tabular}{ll}
\hline & $* *(1)$ Difference-in Differences \\
& Estimates (Arm*Post-treatment) \\
\hline Baseline - Post-treatment One & $-1.393(\mathrm{p}<0.0001)$ \\
Baseline - Post-treatment Two & $-1.204(\mathrm{p}<0.0001)$ \\
\hline
\end{tabular}

**(1) Difference-in-Difference estimator is the interaction between treatment arms and post-treatment scores.

*(2) The difference-in differences estimates were reported as incidence rate ratios.

The difference-in-differences analysis was used to estimate the impact of behavior and REBT therapies in treating 
conduct disorder among juvenile delinquents in Kabete rehabilitation school as shown in Table 4. The difference-indifference estimator equals the average change in outcomes in the experimental group after the average change in conduct disorder symptom reduction in the control group were subtracted. The analysis showed that the impact of the intervention resulted in a statistically significant reduction of the proportion of conduct disorder among the experimental group as compared to the control group at post-treatment one $(\mathrm{p}<0.0001)$ and post-treatment two $(\mathrm{p}<0.0001)$ after controlling for class.

Table 5 shows the mean scores of conduct disorder in both the experimental and control group. The scores were analysed at baseline, post-treatment one at three months and post-treatment two at six months.

Table 5. Mean Scores at Baseline and Post-Treatment for Control and Experimental.

\begin{tabular}{llll}
\hline & Mean scores (SD) & & \\
\cline { 2 - 4 } & Pre-treatment/baseline $(\mathbf{n = 4 7 )}$ & Treatment One/3 months (n=47) & Treatment Two/6 months (n=47) \\
\hline Control & $14.94(3.953)$ & $14.57(4.292)$ & $11.81(4.332)$ \\
Experimental & $19.96(5.069)$ & $10.81(2.983)$ & $8.26(2.625)$ \\
\hline
\end{tabular}

The study revealed a steady decline in the mean scores for control and experimental at the repeated measures as it is displayed in Table 5. Control mean scores declined from $14.94(\mathrm{SD} \pm 3.953)$ at baseline to $11.81(\mathrm{SD} \pm 4.332)$ at posttreatment two. The experimental group mean scores declined from a baseline of 19.96 (SD \pm 5.069 ) to a post-treatment two of $8.26(\mathrm{SD} \pm 2.625)$. This revealed a significant drop in conduct disorder symptoms in mean scores between baseline and post-treatment one and post-treatment two in the experimental group as opposed to the control group.

Table 6 used sample paired T-test to determine the statistical significance in the paired mean difference scores between baseline and post-treatment one and post-treatment two.

Table 6. Mean Outcome Difference Scores from Baseline to Post-Treatment at 3 Month and 6 Month Follow-Up for Control and Experimental Groups.

\begin{tabular}{|c|c|c|c|c|c|}
\hline & \multicolumn{5}{|c|}{ Mean difference scores (SD) } \\
\hline & Baseline & Treatment One $(n=47)$ & p-value & Treatment Two $(n=47)$ & p-value \\
\hline Control & & $0.362(2.981)$ & $\mathrm{p}=0.410$ & $3.128(3.362)$ & $\mathrm{p}<0.0001$ \\
\hline Experimental & & $9.149(3.617)$ & $\mathrm{p}<0.0001$ & $11.702(4.736)$ & $\mathrm{p}<0.0001$ \\
\hline
\end{tabular}

As shown in Table 6, the study revealed mean difference scores between baseline and post-treatment one of 0.362 (SD $\pm 2.981)$ in the control group and this was not statistically significant $(\mathrm{p}=0.410)$. However, at post-treatment two the mean difference scores was $3.128(\mathrm{SD} \pm 3.362)$ and this was statistically significant $(\mathrm{p}<0.0001)$. With respect to experimental group, the study showed statistically significant difference in mean difference scores at both post-treatment one and post-treatment two $(\mathrm{p}<0.0001)$.

Table 7 was generated using Cohen's $d$ method of calculating effect size for both experimental and control group at baseline and post-treatment after three and six months.

Table 7. Effect Sizes from Baseline to Post-Treatment at 3 and 6 Month Follow-Up.

\begin{tabular}{lllll}
\hline & \multicolumn{2}{l}{ Pre/3-month post-treatment $(\mathbf{n}=\mathbf{4 7})$} & \multicolumn{2}{l}{ Pre/6-month post-treatment $(\mathbf{n}=\mathbf{4 7})$} \\
\cline { 2 - 5 } & Effect sizes & $\mathbf{9 5 \%}$ CI & Effect sizes & $\mathbf{9 5 \%}$ CI \\
\hline Control & 0.091 & $-0.735-0.916$ & 0.763 & $0.066-1.592$ \\
Experimental & 2.224 & $1.392-3.056$ & 2.930 & $2.123-3.737$ \\
\hline
\end{tabular}

Table 7 shows statistically significant effect sizes for both control and experimental group at post-treatment one and post-treatment two. With regard to the control group, the Cohen's $d$ effect size value for post-treatment one $(\mathrm{d}=0.091)$ was small while at post-treatment two $(\mathrm{d}=0.763)$ was a large effect size. For experimental group, very large effect sizes were noted at post-treatment one and post-treatment two. Cohen's $d$ effect size value for post-treatment one $(\mathrm{d}=2.224)$ and post-treatment two $(\mathrm{d}=2.930)$ suggested a very large practical significance for the experimental group. Therefore, this was an indication that behavior and REBT therapies had an impact at post-treatment one and post-treatment two among juvenile delinquents in the experimental group.

\section{Discussion}

Behavior and REBT therapies were effective in treating conduct disorder among juvenile delinquents in the experimental group. These therapies used operant conditioning, emotional regulation training, cognitive restructuring and problem solving skills training. These techniques addressed the key aspects of a child's functioning that is cognition, emotions and behavior leading to the reduction of conduct disorder symptoms. In the control group, this study established some slight behavior change among the respondents. This may have been caused by the brief interactions with the questionnaire which specifically addressed problem behaviors.

Conduct disorder is a persistent behavior problem which is highly prevalent among adolescents. Compared to the general population, juvenile delinquents record a higher prevalence of conduct disorder $[15,20]$. Effects of conduct disorder on children and adolescents-rejection, strained relationships, poor academic performance, crime, later develop to 
antisocial disorder if left untreated. Studies have indicated high prevalence of conduct disorder in correctional facilities [16]. Further research has shown the effectiveness of specific interventions in treating the disorder. This study however used a combination of behavioral and rational emotive behavior therapies as an intervention in the treatment of conduct disorder.

The experimental and control group were government institutions for boys only. The institutions also offered formal education and vocational training to the juvenile delinquents. Moreover, both institutions provided boarding facilities to the juveniles. A Pearson's chi-square test indicated that there was no significant difference in religion between the two institutions. Further analysis also showed that there was no significant difference in employment status of respondents' parents/caregivers in the two groups. Therefore both the control and experimental were two comparable groups. There was however a significant difference in class but this was controlled during analysis.

As far as treatment was concerned, the experimental group received both behavior and rational emotive behavior therapies for a period of six months. This study indicated a highly significant difference $(\mathrm{p}<0.0001)$ based on marginal mean between baseline, post-treatment one and posttreatment two. The result was generated after controlling for class.

The experimental group recorded a huge symptom reduction between baseline and post-treatment compared to the control group. At baseline, the experimental group had a mean of 19.96 (SD: 5.069) and at post-treatment one, the mean reduced to 10.81 (SD: 2.983). In the first three months of the treatment, rational emotive behavior therapy was administered. Therapy aimed at addressing cognitive, emotive and behavioral issues using the problem solving skills training $[9,34,42,50]$. The decline in scores between baseline and post-treatment one was an indication that rational emotive behavior therapy using problem solving skills training was effective in treating conduct disorder. This study was comparable to other studies which demonstrated the use of REBT as an effective intervention [41, 54, 55, 59].

In addition, the experimental group indicated a decline in the mean conduct disorder scores from 10.81 (SD: 2.983) to 8.26 (SD: 2.625) during post-treatment two. At this period, behavior therapy using operant conditioning as a model was administered. This included reinforcement, extinction and punishment, focusing on behavior change, unlearning destructive behavior and learning socially acceptable behavior $[3,4,44,60]$. The change in the mean scores in post-treatment two demonstrated that behavior therapy was effective in treating conduct disorder. These results compared to other studies that indicated a significant reduction of behavior problem symptoms by using behavior therapy [47, 49].

In the control group, there was a decline in symptom reduction between baseline, post-treatment one and two without treatment. At baseline, the control group had a mean score of 14.94 (SD: 3.953) and after three months, the mean score dropped to 14.57 (SD: 4.292). After six months, the control group further declined the mean score from 14.57 (SD: 4.292) to 11.81 (SD: 4.332). The group interacted with the questionnaire three times and probably the respondents started reflecting on their behavior as they were scoring for themselves. The insight may have been received as part of psycho-education since it is ranked among the most effective programs that lead to behavior change among juveniles [61].

Further analysis using the difference-in-difference indicated a highly statistical significant reduction of symptoms $(\mathrm{p}<0.0001)$ in the experimental group compared to the control group (Table 4). This was recorded both at posttreatment one (-1.393) and post-treatment two (-1.204). The difference-in-difference negative scores indicated that, compared to the control group, there was a significant symptom reduction in the experimental group. Although the control group recorded some decline, these results showed that comparing the two groups, the experimental group had registered tremendous change.

Moreover, the experimental group indicated statistically significant differences in post-treatment one and two. This meant that the rational emotive behavior therapy administered in the first three months was effective in treating conduct disorder. Moreover, behavior therapy administered in the last three months was effective as well. This finding was comparable to other studies which have indicated that using a combination of therapies was effective in treating conduct disorder [5, 8, 34, 62].

This study established significant effect sizes at posttreatment one and post-treatment two $(\mathrm{d}=2.224, \mathrm{~d}=2.930$ respectively) in the experimental group. Using both REBT and behavior therapies in this study caused a decline in conduct disorder symptoms. Children with conduct disorder present with cognitive deficiencies, poor perception, aggression, and emotional dysregulations in addition to poor social skills. REBT addressed irrational thoughts, beliefs and perceptions, emotional regulation and problem solving skills. Behavior therapy focused on learning and unlearning behavior through reinforcement. The effect sizes realized during the two treatment phases were as a result of therapy. This study therefore concluded that REBT and behavior therapies were effective in treating conduct disorder among juvenile delinquents in the two rehabilitation schools.

The use of behavioral and REBT therapies as interventions for conduct disorder was effective. The treatment recorded high effect sizes at post-treatment one and two. The decline in symptoms at post-treatment one was greater compared to treatment two. Post-treatment one addressed self-perception, irrational beliefs and offered problem solving skills training while post-treatment two administered behavioral therapy (operant conditioning). Combining both REBT and behavioral therapies proved to be effective in treating conduct disorder among juvenile delinquents.

\section{Conclusion}

There were significant reductions in the mean scores for conduct disorders in the treatment group at both 3 month and 
6 month post -behavioral and rational emotive behavior therapies intervention amongst the incarcerated juvenile delinquents in the study population. This study established that behavioral and rational emotive behavior (REB) therapy was effective in treating conduct disorder among incarcerated juvenile delinquents in the study population both at 3 months and at 6 months post - intervention. The study also demonstrated that the intervention had significant practical significance in the treatment of the incarcerated juvenile delinquents. For rehabilitation of incarcerated juvenile delinquents, it is therefore important to consider integration of behavioral and REBT therapies in the juveniles' rehabilitation program in management of conduct disorders.

\section{Acknowledgements}

Scholar Leaders International.

\section{References}

[1] The British Psychological Society \& The Royal College of Psychiatrists, Antisocial behavior and conduct disorders in children and young people: Recognition, intervention and management, Great Britain: Stanley L. Hunt Printer Ltd, 2013.

[2] R. Sagar, B. N. Patra and V. Patil, "Cinical practice guidelines for the management of conduct disorder," Indian Journal of Psychiatry, vol. 61, no. 2, pp. 270-276, 2019.

[3] F. Mairead, S. McGilloway', B. Tracey, H. Judy, S. S. M and D. Michael, "Behavioral and cognitive behavioral group-based parenting programmes for early-onset conduct problems in children aged 3 to 12 years (Review)," Evidence-Based Child Health: A Cochrane Review Journal, vol. 2, pp. 318-692, 2012.

[4] M. Greger-Moser, "Child problem, executive functions, and treatment: The role of executive functions in treatment of children with conduct disorder," The Undergraduate Journal of Psychology, vol. 21, pp. 1-15, 2008.

[5] N. N. Singh, G. E. Lancioni, J. D. Singh, A. S. Winton, M. Sabaawi, R. G. Wahler and J. Singh, "Adolescents with conduct disorder can be mindful of their aggressive behavior," Journal of Emotional and Behavioral Disorders, vol. 15, no. 1, pp. 56-63, 2007.

[6] P. J. Frick and A. S. Morris, "Temperament and developmental pathways to conduct problems," Journal of Clinical Child and Adolescent Psychology, vol. 33, no. 1, pp. 54-68, 2004.

[7] P. J. Frick, "Effective interventions for children and adolescents with conduct disorder," Canadian Journal of Psychiatry, vol. 46, pp. 597-608, 2001.

[8] A. E. Kazdin, "Psychosocial treatments for conduct disorder in children and adolescents," in A guide to treatments that work 2nd ed, New York, Oxford University Press, 2002, pp. 146.

[9] L. L. Baker and K. Scarth, Cognitive behavioral approaches to treating children and adolescents with conduct disorder, Ontario: Children's Mental Health, 2002.

[10] M. K. Ehrensaft, "Interpersonal relationships and differences in the development of conduct problems," Clinical Child and Family Psychology Review, vol. 8, no. 1, pp. 39-63, 2005.

[11] E. Brestan and S. M. Eyberg, "Effective psychosocial treatments of conduct-disordered children and adolescents: 29 years, 82 studies and 5, 272 kids," Journal of Clinical Child Psychology, vol. 27, no. 2, pp. 180-189, 1998.

[12] C. Waddell, W. Wong, J. Hua and R. Godderis, "Preventing and treating conduct disorder in children and youth," Children's Mental Health Policy Research Program, vol. 1, no. 3, pp. 1-30, 2004.

[13] E. J. Mash and D. A. Wolfe, Abnormal child psychology 4th ed, Australia: Wadsworth Cengage Learning, 2010.

[14] M. K. Nock, A. E. Kazdin, E. Hiripi and R. C. Kessler, "Prevalence, subtypes, and correlates of DSM-IV conduct disorder in the national comorbidity survey replication," Psychol Med, vol. 36, no. 5, pp. 699-710, 2006.

[15] O. Colins, V. Robert, V. Paul, M. Monica, B. Erick and D. Theo, "Psychiatric disorders in detained male adolescents: A systematic literature review," Canadian Journal of Psychiatry, vol. 55 , no. 4 , pp. 255-263, 2010.

[16] S. Fazel, H. Doll and L. Niklas, "Mental disorders among adolescents in juvenile detention and correctional facilities: A systematic review and metaregression analysis of 25 surveys," Journal of Americal Academy Child Adolescent Psychiatry, vol. 47, no. 9, pp. 1010-1019, 2008.

[17] L. A. Teplin, K. M. Abram, G. M. McClelland, M. K. Dulcan and A. A. Mericle, "Psychiatric disorders in youth in juvenile detention," Arch Gen Psychiatry, vol. 59, no. 12, pp. 11331143, 2002.

[18] S. Sarkhel, V. K. Sinha, M. Arora and D. Pushpal, "Prevalence of conduct disorder in school children in Kanke," Indian Journal of Psychiatry, vol. 48, no. 3, pp. 159-164, 2006.

[19] A. I. Frank-Briggs and E. D. Alikor, "Conduct disorder amongst children in an urban school in Nigeria," The Nigerian Health Journal, vol. 8, no. 3-4, pp. 44-47, 2008.

[20] L. V. Okwara, Prevalence of psychiatric morbidity among juvenile offenders committed to Borstal institutions in Kenya, Nairobi, 2010.

[21] M. Maru, D. M. Kathuku and D. M. Ndetei, "Psychiatric morbidity among children and young persons appearing in the Nairobi juvenile court, Kenya," East African Medical Journal, vol. 80, no. 6, pp. 226-232, 2003.

[22] K. Mueser, A. G. Crocker, L. B. Frisman, R. E. Drake, N. H. Covell and S. M. Essock, "Conduct disorder and antisocial personality disorder in persons with severe psychiatric and substance use disorders," Schizophrenia Bulletin, vol. 32, no. 4, pp. 626-636, 2006.

[23] S. P. Sells, W. E. Kristin and T. E. Smith, "Reducing adolescents oppositional and conduct disorders: An experimental design using the parenting with love and limits model," Professional Issues in Criminal Justice, vol. 6, no. 3/4, pp. 9-30, 2011.

[24] I. Bretherton, "The origins of attachment theory:John Bowlby and Mary Ainsworth," Developmental Psychology, vol. 28, pp. 759-775, 1992. 
[25] K. A. Carmody, M. E. Haskett, J. Loehman and R. A. Roderick, "Physically abused children's adjustment at the transition to school: Child, parent and family factor," $J$ Child Fam Stud, vol. 24, no. 4, pp. 957-969, 2015.

[26] D. Pardini and P. J. Frick, "Multiple developmental pathways to conduct disorder: Current conceptualization and clinical implications," Journal of the Canadian Academy of Child and Adolescent Psychiatry, vol. 22, no. 1, pp. 20-25, 2013.

[27] M. J. Cenat, H. Martine, B. Martin, L. Francine and G. Mireille, "Delinquent behaviors among students exposed to family violence in Quebec school," Adolescencia \& Sauda, vol. 12, no. 3, pp. 43-52, 2015.

[28] M. O. Ojo, "A sociological review of issues on juvenile delinquency," The Journal of International Social Research, vol. 5, no. 21, pp. 468-482, 2012.

[29] J. O. Omboto, O. Gerald, O. Odera and E. Ayugi, "Factors influencing youth crime and juvenile delinquency," International Journal of Research in Social Science, vol. 1, no. 2, pp. 18-21, 2013.

[30] C. Yuping, L. Longfei, Z. Xingfu, Y. Zhang, X. Guo, Y. Zhang and X. Luo, "Effects of exposure to domestic physical violence on children's behavior: A chinese community-based sample," Journal of Child Adolescent Trauma, vol. 9, no. 2, pp. 127-135, 2016.

[31] J. Haugaard, Child psychopathology, Boston: McGraw Hill Higher Education, 2008.

[32] J. G. Johnson, P. Cohen, S. Kasen and E. Smailes, "Association of maladaptive parental behavior with psychiatric disorder among parents and their offspring," Arch Gen Psychiatry, vol. 58, no. 5, pp. 453-460, 2001.

[33] R. Searight, F. Rottnek and S. Abby, "Conduct disorder: Diagnosis and treatment in primary care," American Family Physician, vol. 63, no. 8, pp. 1579-1589, 2001.

[34] C. Warner-Metzger and S. M. Riepe, "Disruptive behaviro disorders in children and adolescents," EchappellTDMHSASResearch Team, pp. 132-160, 2013.

[35] H. Jami, "Psycho-social risk factors of conduct disorder among institutionalized children," Journal of Gender and Social Issues, vol. 16, no. 1, 2017.

[36] D. F. Bjorklund and C. H. Blasi, Child and adolescent development: An integrated approach, Australia: Wadsworth Cengage Learning, 2012.

[37] B. A. Marina, B. Ryan, M. Steve, M. Matt and L. G. William, "Disentangling the relative contribution of parental antisociality and family discord to child disruptive disorders," Personality Disorders, vol. 4, no. 3, pp. 239-246, 2013.

[38] J. Murray and D. P. Farrington, "Risk factors for conduct disorder and delinquency: Key findings from longitudinal studies," Canadian Journal of Psychiatry, vol. 55, no. 10, pp. 633-642, 2010.

[39] J. R. Ingram, J. W. Patchin, B. M. Huebner, J. D. McCluskey and T. S. Bynum, "Parents, friends and serious delinquency: An examination of direct and indirect effects among at-risk early adolescents," Criminal Justice Review, vol. 32, no. 4, pp. 380-400, 2007.

[40] P. J. Frick, "Developmental pathways to conduct disorder:
Implications for serving youth who show severe aggression and antisocial behavior," Psychology in the Schools, vol. 41, no. 8, pp. 823-834, 2004.

[41] T. Banks and P. Zionts, "Rational emotive behavior therapy used with children and adolescents in educational settings: A review of literature," Journal of Rational Emotive Cognitive Behavior Therapy, vol. 27, pp. 51-65, 2009.

[42] G. Corey, Theory and practice of counseling and psychotherapy 8th ed, Canada: Thomson Brooks/Cole, 2009.

[43] D. Hothersall, History of psychology 4th ed, Boston: McGraw Hill, 2004.

[44] R. A. Powell, L. P. Honey and D. G. Symbaluk, Introduction to learning and behavior 3rd ed, Australia: Wadsworth Cengage Learning, 2009.

[45] J. R. Weisz, A. Jensen-Doss and K. M. Hawley, "Youth psychotherapy outcome research: A review and critique of the evidence base," Youth Psychotherapy Research, vol. 56, pp. 337-363, 2005.

[46] D. C. Gottfredson, "School-based crime prevention," n.d. [Online]. Available: www.ncjrs.gov/works/chap5.htm.. [Accessed 2013].

[47] L. G. Reddy, V. Shyamala, A. Kusuma and K. P. Santha, Antisocial behavior in students: Detection and management, New Delhi: Discovery Publishing House, 2005.

[48] J. S. Stumphauzer, Helping delinquents change: A treatment manual of social learning approaches, New York: The Haworth Press, 1986.

[49] J. R. Weisz, A. Jensen-doss and K. M. Hawley, "Empiricallytested psychotherapies for youth internalizing and externalizing problems and disorders," Child and Adolescent Psychiatric Clinics of North America, vol. 13, pp. 729-815, 2004.

[50] T. Banks, "rational emotive behavior therapy with diverse student populations: Meeting the mental health needs of all students," Multicultural Learning and Teaching, vol. 7, no. 2, pp. 1-18, 2012.

[51] D. David, S.-T. Aurora, E. Kallay and B. Macavei, "A synopsis of rational-emotive behavior therapy: Fundamental and applied research," Journal of Rational-Emotive and Cognitive-Behavior Therapy, vol. 23, no. 3, pp. 175-221, 2005.

[52] D. David, C. Cotet, S. Matu, C. Mogoase and S. Stefan, "50 years of rational-emotive and cognitive-behavioral therapy: A systematic review and meta-analysis," Journal of Clinical Psychology, vol. 74, no. 3, pp. 304-318, 2018.

[53] D. Stan and N. L. Charisse, "Youth voice project," Student Insights into Bullying and Peer Mistreatment, pp. 1-4, 2013.

[54] V. G. Kumar, "Impact of rational-emotive behavior therapy on adolescents with conduct disorder," Journal of the Indian Academy of Applied Psychology, vol. 35, pp. 103-111, 2009.

[55] B. G. Morris, "A rational-emotive treatment program with conduct disorder and attention deficit hyperactivity disorder adolescents," Journal of Rational-Emotive and Cognitive Behavior Therapy, vol. 11, no. 3, pp. 123-134, 1993.

[56] C. Ebustani, B. Adam, M. I. Jonathan, C. F. Bruce and R. W. John, "The youth self report: Applicability and validity across younger and older youths," Journal of Clinical Child and Adolescent Psychology, vol. 40, no. 2, pp. 338-346, 2011. 
[57] T. M. McDevitt and J. E. Ormrod, Kohlberg's three levels and six stages of moral reasoning, Pearson Ally Bacon: Prentice Hall, 2010.

[58] I. A. Bordin, M. M. Rocha, P. S. Cristianes, T. Achenbach and L. A. Rescorla, "Child behavior checklist (CBCL), youth-selfreport (YSR) and teacher's report form (TRF): An overview of the development of the original and Brazilian versions," Cad. Saude Publica, Rio de Janeiro, vol. 29, no. 1, pp. 13-28, 2013.

[59] J. McGuire, Cognitive behavioral approaches: An introduction to theory and research, United Kingdom: University of Liverpool, 2000.
[60] C. C. Hewage, "Behavior therapy for medical practice," Galle Medical Journal, vol. 12, no. 1, pp. 45-48, 2007.

[61] D. Sukhodolsky and V. Ruchkin, "Evidence-based psychsocial treatments in the juvenile justice system," Child and Adolescent Psychiatric Clinics of North America, vol. 15, no. 2, pp. 501-516, 2006.

[62] M. Lali, M. Malekpour, H. Molavi, A. Abedi and K. Asgari, "The effects of parent management training, problem-solving skills training and the eclectic training on conduct disorder in Iranian elementary school students," International Journal of Psychological Studies, vol. 4, no. 2, pp. 154-161, 2012. 